\title{
Validation of a SPME-GC Method for Azoxystrobin and Pyraclostrobin in Blueberries, and Their Degradation Kinetics
}

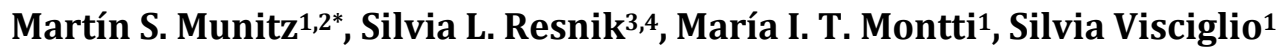 \\ ${ }^{1}$ Facultad de Ciencias de la Alimentación, Universidad Nacional de Entre Ríos, Concordia, Argentina \\ ${ }^{2}$ Agencia Nacional de Promoción Científica y Tecnológica, Buenos Aires, Argentina \\ ${ }^{3}$ Departamentos de Química Orgánica e Industrias, Facultad de Ciencias Exactas y Naturales, \\ Universidad de Buenos Aires, Buenos Aires, Argentina \\ ${ }^{4}$ Comisión de Investigaciones Científicas de la Provincia de Buenos Aires, La Plata, Argentina \\ Email: * munitzm@fcal.uner.edu.ar
}

Received 2 July 2014; revised 17 August 2014; accepted 12 September 2014

Copyright (C) 2014 by authors and Scientific Research Publishing Inc.

This work is licensed under the Creative Commons Attribution International License (CC BY). http://creativecommons.org/licenses/by/4.0/

(c) (i) Open Access

\begin{abstract}
Analytical method for the residues of strobilurins azoxystrobin and pyraclostrobin in blueberries was developed. Fungicide residues were determined by solid-phase microextraction (SPME) coupled to gas chromatography with micro-electron capture detector. The effect of pH values and fiber coatings were studied. The SPME fiber coating selected was $100 \mu \mathrm{m}$ PDMS. The method is selective with adequate precision and high accuracy and sensitivity. Recoveries ranged within the $100 \%-106 \%$ range for azoxystrobin, and $96 \%-106 \%$ range for pyraclostrobin; and detection and quantification limits were 2.0 and $6.0 \mu \mathrm{g} / \mathrm{kg}$ for azoxystrobin, and 26.0 and $86.0 \mu \mathrm{g} / \mathrm{kg}$ for pyraclostrobin, respectively. Statistical parameters indicated the occurrence of matrix effect; consequently calibration was performed on spiked samples. Degradation of azoxystrobin and pyraclostrobin was studied in blueberry fields located in Concordia, Argentina, with fruits from Emerald and Jewel varieties. The degradation of these fungicides in both blueberry varieties studied followed a first order rate kinetics, and the half-life for azoxystrobin was 11.6 and 17.8 days for Emerald and Jewel cultivars; and for pyraclostrobin was 5.5 and 8.0 days, respectively.
\end{abstract}

\section{Keywords}

Blueberries, Azoxystrobin, Pyraclostrobin, Degradation Kinetics, SPME/GC

\footnotetext{
${ }^{*}$ Corresponding author.
}

How to cite this paper: Munitz, M.S., Resnik, S.L., Montti, M.I.T. and Visciglio, S. (2014) Validation of a SPME-GC Method for Azoxystrobin and Pyraclostrobin in Blueberries, and Their Degradation Kinetics. Agricultural Sciences, 5, 964-974. 


\section{Introduction}

Azoxystrobin [methyl (2E)-2-\{2-[6-(2-cyanophenoxy)pyrimidin-4-yloxy]phenyl $\}$-3-methoxyacrylate- $-\mathrm{C}_{22} \mathrm{H}_{17} \mathrm{~N}_{3} \mathrm{O}_{5}$ ] and pyraclostrobin [methyl 2-[1-(4-chlorophenyl)pyrazol-3-yloxymethyl]- $N$-methoxycarbanilate- $\left.-\mathrm{C}_{19} \mathrm{H}_{18} \mathrm{CIN}_{3} \mathrm{O}_{4}\right]$ are two of the most important fungicides used in blueberry fields (Figure 1(a) and Figure 1(b)). They have been determinated in different products by gas chromatography [1] or gas chromatography with mass spectrometry [2]-[9] or by liquid chromatography-mass spectrometry [10]-[13].

Blueberries, like most fruits, are prone to fungal spoilage. Contamination by different moulds can occur during pre-harvesting, harvesting and blueberry processing [14]-[19]. To avoid this situation, the application of fungicides, as azoxystrobin and pyraclostrobin, is a common practice in the field. However, the concentration of these pesticides in the berries is limited by legislation. For example, in Europe, the Regulation (EC) No. $396 / 2005$ [20]. The current EU MRLs are $5.0 \mathrm{mg} / \mathrm{kg}$ for azoxystrobin and $3.0 \mathrm{mg} / \mathrm{kg}$ for pyraclostrobin.

The aims of the present study were the development and validation of an accurate, efficient and precise solid phase microextraction-gas chromatography (SPME-GC) method for determination of azoxystrobin and pyraclostrobin in blueberries, and the study of their degradation kinetics.

\section{Materials and Methods}

\subsection{Solutions and Reagents}

Azoxystrobin and pyraclostrobin standards of high purity (>98\%) were supplied by Sigma-Aldrich (Seelze, Germany). The stock solutions (1 g/l) were prepared by dissolving the standards in methanol HPLC grade (99.9\%) purchased by Sintorgan (Buenos Aires, Argentina), and stored under freezing condition $\left(-18^{\circ} \mathrm{C}\right)$ in dark bottles sealed with PTFE/silicone caps. The working solutions were prepared daily by diluting with deionized water obtained from an E-pure water purification system (Barnstead/Thermolyne, Bedford, MA, USA). Sodium hydroxide was purchased from Biopack (Buenos Aires, Argentina).

A powder of 50\% azoxystrobin and $12.8 \%$ pyraclostrobin under the trade names or Amistar (Syngenta Agro S.A., Argentina) and Bellis (BASF, Argentina), respectively, were used in the experiments. The concentrations were confirmed by analyzing these powders with the methodology developed in this paper against the standard prepared as described in the paragraph above.

\subsection{Chromatographic Conditions}

Gas chromatographic (GC) analyses were carried out on an Agilent 6890N gas chromatograph equipped with a micro-electron capture detector ( $\mu \mathrm{ECD}$ ), a split-splitless injection port, a $0.75 \mathrm{~mm}$ ID liner and a fused silica capillary column HP-5MS (30 $\mathrm{m} \times 0.25 \mathrm{~mm}$ i.d. $\times 0.25 \mu \mathrm{m}$ film thickness). The carrier gas helium was maintained at a constant flow of $1 \mathrm{ml} / \mathrm{min}$. Desorption of the fibers into the injection port was carried out in the splitless mode at $240^{\circ} \mathrm{C}$ for pyraclostrobin and azoxystrobin, during $6.5 \mathrm{~min}$. The oven temperature was programmed as follows: initial temperature of $80^{\circ} \mathrm{C}(6 \mathrm{~min})$, increased at a rate of $80^{\circ} \mathrm{C} / \mathrm{min}$ up to $280^{\circ} \mathrm{C}(10 \mathrm{~min})$. The detector temperature was $300^{\circ} \mathrm{C}$. The SPME holder for manual use and fibers coated with $100 \mu \mathrm{m}$ PDMS (polydimethylsiloxane, apolar), $65 \mu \mathrm{m}$ CWX-DVB (carbowax-divinylbenzene, polar) and $85 \mu \mathrm{m}$ PA (polyacrylate, polar),<smiles>CO/C=C(/C(=O)OC)c1ccccc1Oc1cc(Oc2ccccc2C#N)ncn1</smiles>

(a)

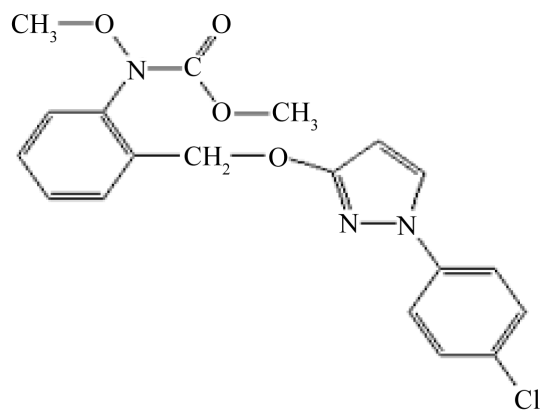

(b)

Figure 1. Chemical molecular structure of azoxystrobin (a) and pyraclostrobin (b). 
were purchased from Supelco (Bellefonte, PA, USA). The three fibers were conditioned by heating in the GC injection port and reused for several analyses following the manufacturer recommendations. The extraction procedure was performed in $8 \mathrm{ml}$ amber glass vials and the solutions were stirred at $2000 \mathrm{rpm}$ with a magnetic stirrer.

\subsection{Field Experiments}

The fungicide application was carried out by qualified personnel from the field. The plots selected for the experiment received all routine agricultural practices except pesticide application during 2010-2011 harvest seasons. Field study was made in Concordia Department where Amistar and Bellis are used against different fungi by all the producers.

The plots (approximately $850 \mathrm{~m}^{2}$ ) have from 20 to 25 lines of plants with 15 to 20 bushes each. Samples were collected in zig-zag every 4 lines and 3 bushes, from the bottom, the middle and the top parts of the plants, and from the four cardinal points (approximately $300 \mathrm{~g}$ per sample).

Two commercial varieties of blueberry, Emerald and Jewel, were studied during 2010-2011 harvest season.

For dissipation study, sampling was started $12 \mathrm{~h}$ after the application, to allow enough time for the emulsion to dry, and repeated $1,3,4,6,10,15$, and 20 days afterwards to determine the residues of pyraclostrobin and 10, $16,21,27,31,36,41,48,57,66$ and 69 for azoxystrobin, in blueberries. Blueberry traders established a period of time between successive applications of each fungicide. A new application of pyraclostrobin is commonly made in the fields after a rainy day because the period of time established between applications is of 6 days. On the other hand, azoxystrobin is not normally used more than once during production, because 90 days have to pass after an application in the field. These are the reasons why the samples were picked in different periods of time.

\subsection{Extraction Procedure}

Samples (300 blueberries) were blended using a food cutter. A 10 g portion was weighted in a $25 \mathrm{ml}$ centrifugal tube and extracted with $10 \mathrm{ml}$ water. The solution was vigorously shaked in vortex mixer during $1 \mathrm{~min}$. The $\mathrm{pH}$ was adjusted to 7.0 for azoxystrobin and 5.0 for pyraclostrobin with sodium hydroxide. Then, samples were centrifuged at $3000 \mathrm{rpm}$ during $15 \mathrm{~min}$. Then, the supernatant was filtered with $0.2 \mu \mathrm{m}$ filter in a vacuum maninfold. The extraction was repeated one more time. The procedure was made in triplicate.

For SPME the direct immersion mode was used. Three fibers with different polarity coatings were evaluated to achieve the best extraction. Extraction time and extraction $\mathrm{pH}$ value were operative variables also studied.

\subsection{Method Validation}

The analytical method was validated by evaluating quality parameters such as linearity, precision (repeatability), selectivity, limits of detection and quantification and recovery values.

The SPME conditions were optimized using, firstly standard solutions and secondly, fortified blueberry samples. The calibration curve was constructed with seven concentration levels of spiked samples ranged from 0.005 to $0.75 \mathrm{mg} / \mathrm{kg}$, and from 0.05 to $5 \mathrm{mg} / \mathrm{kg}$ for azoxystrobin and pyraclostrobin, respectively $(\mathrm{n}=10)$. A stock standard solution $(1000 \mathrm{mg} / \mathrm{l})$ of each fungicide was prepared in methanol by weighing approximately $0.025 \mathrm{~g}$ of analyte into $25 \mathrm{ml}$ volumetric flask and diluting to volume. An intermediary mixed standard solution was prepared by dilution in water of the stock standard solutions to give a concentration of $10 \mathrm{mg} / \mathrm{l}$ of each fungicide. All standard solutions were stored in the dark at $4^{\circ} \mathrm{C}$.

Repeatability (expressed as relative standard deviation, RSD \%) was determined by analyzing samples spiked with azoxystrobin and pyraclostrobin at all the concentrations used to determine the linear range $(n=10)$ on the same day.

The selectivity of the proposed methodology was evaluated by observing that there were not interfering peaks at the retention time of azoxystrobin and pyraclostrobin for blank chromatograms of blueberry samples without spiking.

Limits of detection (LOD) and quantification (LOQ) were calculated as three and ten times the signal-to-noise ratio, respectively $(\mathrm{n}=10)$.

For accuracy determination, a recovery evaluation was made. Triplicate blueberry samples were spiked with 
0.01, 0.1 or $0.75 \mathrm{mg} / \mathrm{l}$ of standard solutions for azoxystrobin, and $0.1,1$ and $5 \mathrm{mg} / \mathrm{l}$ for pyraclostrobin.

\subsection{Degradation Kinetics}

STATGRAPHICS Centurion version XV and Origin version 8.6 were the softwares used to perform the statistical analysis and to determine the degradation kinetics and characteristic parameters of the process. Graphics of concentration against time were made for Emerald and Jewel varieties and the maximum correlation coefficient found was used to determine the equation of the best fitting curve. Azoxystrobin and pyraclostrobin losses could be adjusted with a first order kinetics. The equation that represents these models was:

$$
\mathrm{C}_{\mathrm{t}}=\mathrm{C}_{0} \mathrm{e}^{-\mathrm{kt}}
$$

where $\mathrm{C}_{\mathrm{t}}$ is the concentration of azoxystrobin or pyraclostrobin at time $\mathrm{t}(\mathrm{mg} / \mathrm{l}), \mathrm{C}_{0}$ is the initial concentration (mg/l) and $k$ the rate constant (1/day).

The half-life $\left(\mathrm{t}_{1 / 2}\right)$ was defined as time necessary for reduction of the initial pesticide charge to the half, and determined with the equation $\mathrm{t}_{1 / 2}=\ln 2 / k$.

\section{Results and Discussion}

\subsection{Selection of SPME Coating and pH Extraction}

The extraction of azoxystrobin and pyraclostrobin was performed with PDMS, CWX-DVB and PA fiber coatings at different $\mathrm{pH}$ values $(5.0-7.0-9.0)$ in triplicates with 15 minutes of extraction time and $2000 \mathrm{rpm}$. Standard solution of $0.025 \mathrm{mg} / \mathrm{kg}$ of both fungicides was used. In the case of azoxystrobin, the average chromatographic response (RSD) for PDMS were $182 \times 10^{6}(26), 463 \times 10^{6}(6)$ and $158 \times 10^{6}(23)$; for CWX-DVB were $38 \times 10^{6}(2), 100 \times 10^{6}(46)$ and $29 \times 10^{6}(15)$; and for PA were $8 \times 10^{6}(1), 9 \times 10^{6}(29)$ and $8 \times 10^{6}(9)$, for $\mathrm{pH}$ values of 5.0, 7.0 and 9.0, respectively. PDMS had the greatest chromatographic response for each $\mathrm{pH}$ value. The optimum $\mathrm{pH}$ value was 7.0. The results are shown in Figure 2(a).

In the case of pyraclostrobin, the average chromatographic response (RSD) for PDMS were $49 \times 10^{6}$ (3), $4 \times$ $10^{6}(12)$ and $30 \times 10^{6}(48)$; for CWX-DVB were $41 \times 10^{6}(3), 8 \times 10^{6}(29)$ and $6 \times 10^{6}(34)$; and for PA were $6 \times$ $10^{6}$ (7), $0.4 \times 10^{6}(25)$ and $5 \times 10^{6}(10)$, for $\mathrm{pH}$ values of 5.0, 7.0 and 9.0, respectively. In this case, the greatest chromatographic responses were got with PDMS and a pH value of 5.0. The results are shown in Figure 2(b).

Blueberry samples were spiked with $0.1 \mathrm{mg} / \mathrm{kg}$ azoxystrobin and pyraclostrobin and extracted with the PDMS fiber at different $\mathrm{pH}$ values (5.0 - 7.0 - 9.0), to evaluate the matrix effect on the $\mathrm{pH}$. The results are shown in Figure 2(c).

PDMS fiber coating and $\mathrm{pH}$ extraction value of 7.0 were selected to perform the extraction of azoxystrobin in blueberry samples. The fiber was the same for pyraclostrobin, but the $\mathrm{pH}$ value was 5.0. Menezes Filho et al. [21] [22] determined azoxystrobin and pyraclostrobin in mangoes, surface and groundwater samples using PA fiber. Viñas et al. [23] determined both fungicides in baby food using PDMS-DVB fiber.

\subsection{Selection of the SPME and Chromatographic Variables}

The use of sodium chloride to increase the extraction efficiency is well known [24]-[26]. However, the fibers used to be damaged when this salt is added, so consequently, its addition was discarded [23].

Extraction time, stirring speed, desorption time and desorption temperature, were analyzed using PDMS fiber at $\mathrm{pH} 7.0$ for azoxystrobin and 5.0 for pyraclsotrobin.

Extraction time was increased to determine the equilibrium between sample and the PDMS fiber. Figure 3(a) and Figure 3(b) show the influence of extraction time in the adsorption in PDMS fiber for both strobilurins (from 5 and $720 \mathrm{~min}$ ) and demonstrates that total extraction increased with time until $120 \mathrm{~min}$, where the equilibrium was reached. To decrease the overall analysis time, 15 min was selected because calibration curves were reproducible.

The stirring speed was evaluated between 0 and $2000 \mathrm{rpm}$, and it was observed that this variable had an important effect on the extraction. The chromatographic responses for PDMS were continuously increased with the stirring speed up to 2000 rpm (Figure 3(c) and Figure 3(d)). At $1500 \mathrm{rpm}$ the results were similar of those obtained at $2000 \mathrm{rpm}$ for azoxystrobin and pyraclsotrobin, but the dispersion of the replicates was lower. The stirring speed of $1500 \mathrm{rpm}$ was selected for both pesticides. 


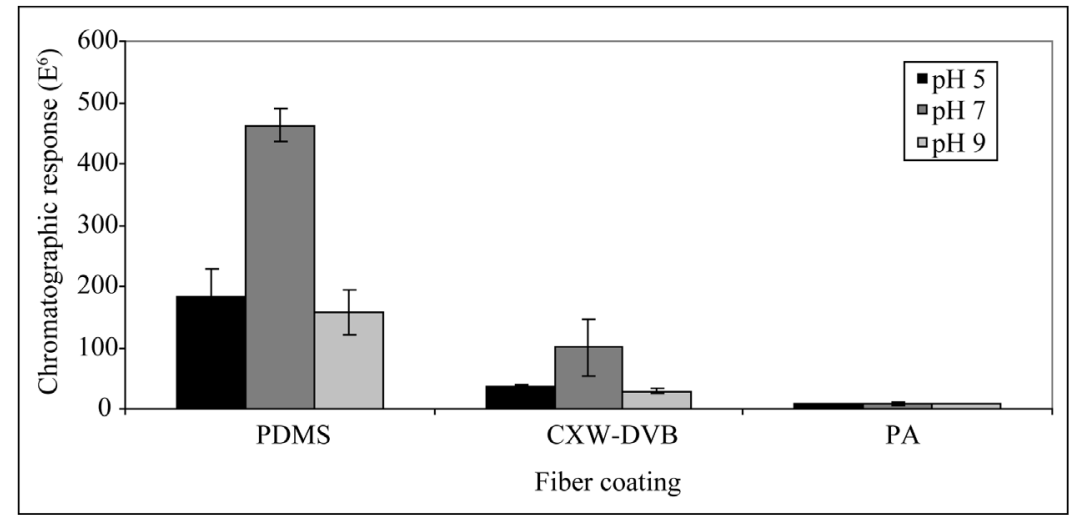

(a)

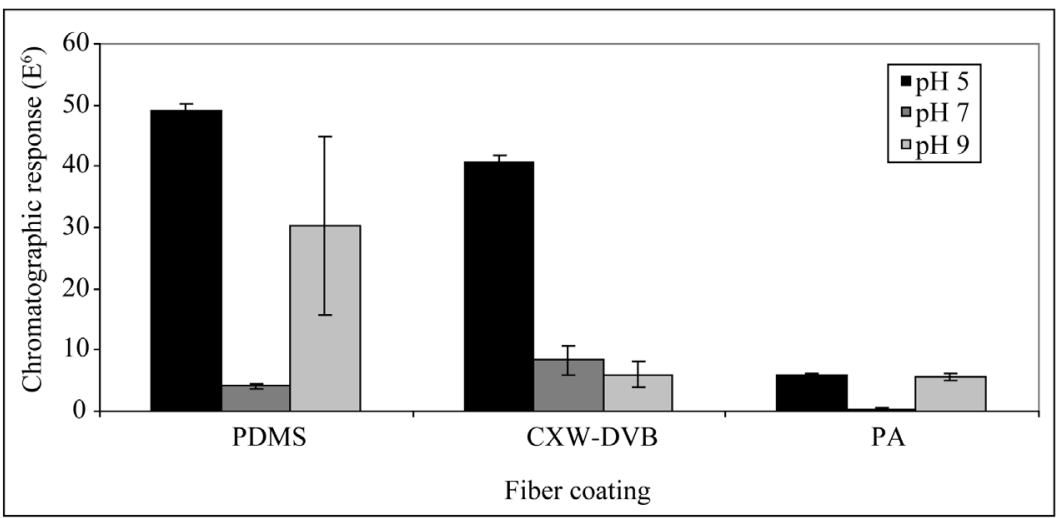

(b)

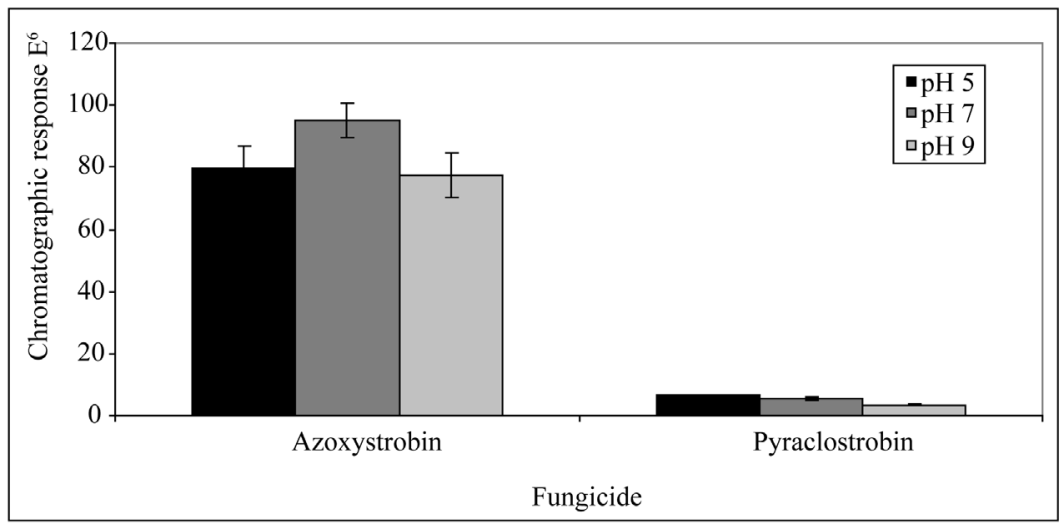

(c)

Figure 2. Evaluation on the chromatographic response of different fiber coatings and $\mathrm{pH}$ values with standard solution of $0.025 \mathrm{mg} / \mathrm{kg}$ of azoxystrobin (a) and pyraclostrobin (b); and evaluation of different $\mathrm{pH}$ values using PDMS in blueberry spiked with $0.1 \mathrm{mg} / \mathrm{kg}$ of azoxystrobin and pyraclostrobin (c).

Optimum desorption conditions were obtained by evaluating the most important variables involved: desorption temperature and time in the injection port. Temperatures of 230, 240, 250 and $260^{\circ} \mathrm{C}$ were tested, founding that the optimum desorption temperature were $240^{\circ} \mathrm{C}$ for pyraclostrobin and $250^{\circ} \mathrm{C}$ for azoxystrobin using PDMS coating with 10 minutes desorption time. However, $240^{\circ} \mathrm{C}$ was selected for both pesticides.

Desorption time was also checked to get the maximum detector response for the fungicides, and to ensure the complete desorption from the fiber. The time was evaluated every 30 seconds at the desorption temperature described above. The time was fixed in 6.5 minutes for both fungicides because at that time no pesticide residues 


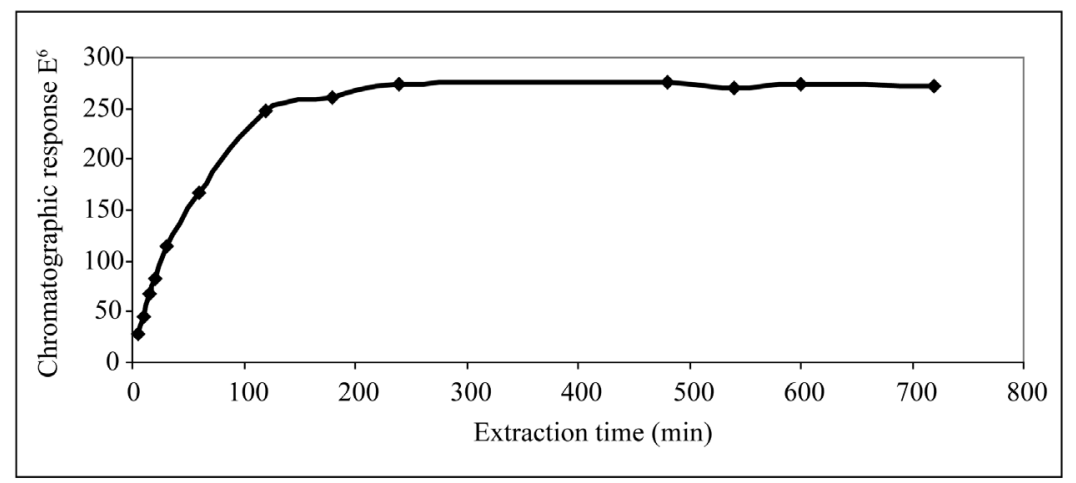

(a)

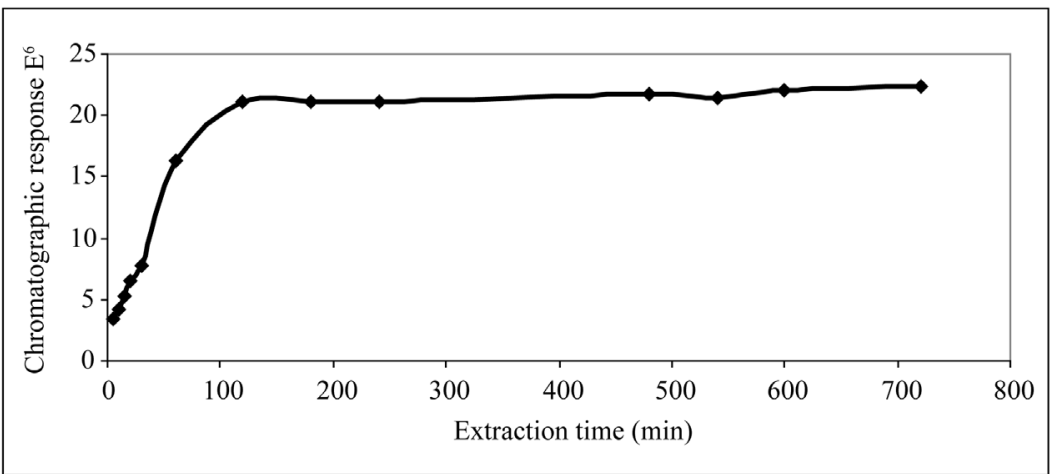

(b)

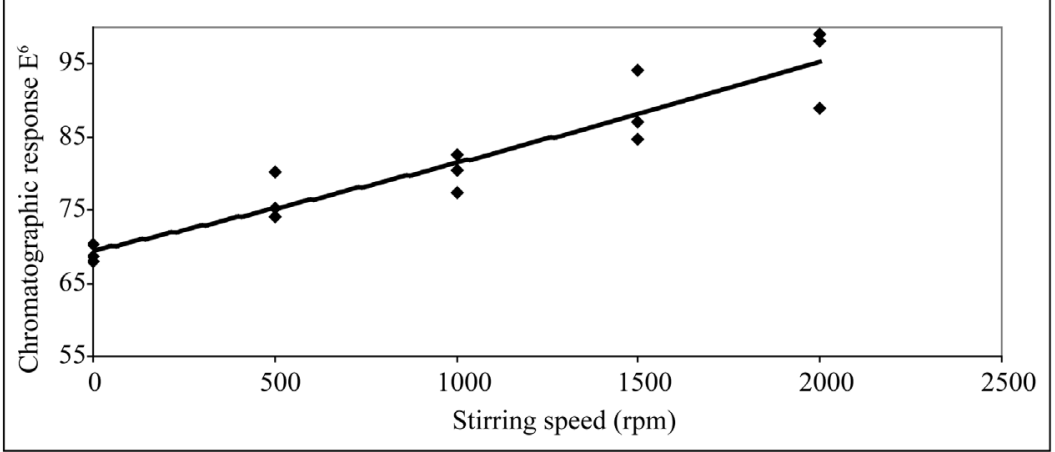

(c)

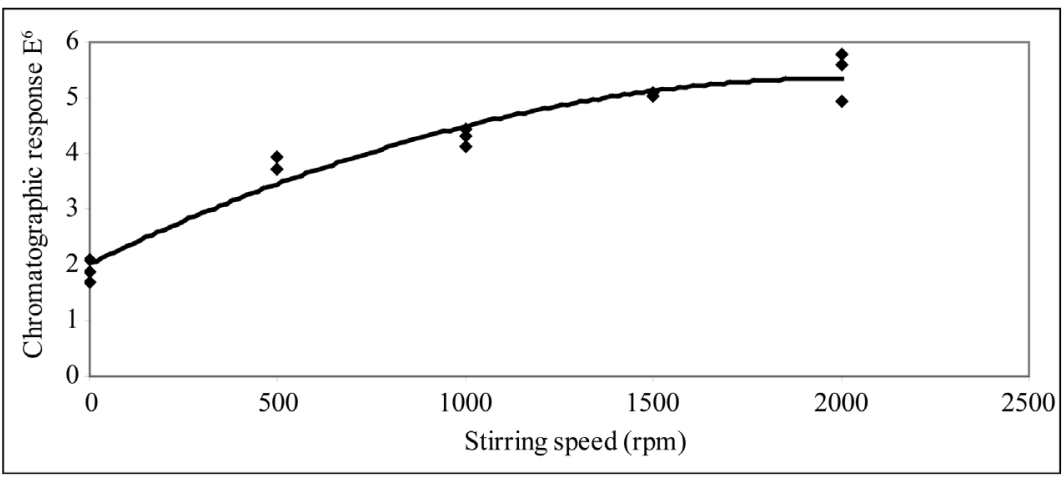

(d)

Figure 3. Influence of the extraction time on azoxystrobin (a) and pyraclostrobin (b); and influence of stirring speed on azoxystrobin (c) and pyraclostrobin (d), using PDMS fiber; $\mathrm{pH}$ 7; $0.025 \mathrm{mg} / \mathrm{kg}$ concentration; desorption time $6.5 \mathrm{~min}$. 
were remained in the fiber after desorption (data not shown).

\subsection{Method Performance}

All the analyses were performed with $8.5 \mathrm{ml}$ vials containing $8 \mathrm{ml}$ of the sample solution. The stir bar was introduced in the vial and the solution was stirred at $1500 \mathrm{rpm}$ during $1 \mathrm{~min}$. After this homogenization step, the PDMS fiber was totally immersed in the solution for $15 \mathrm{~min}$. The adsorption temperature was programmed at $25^{\circ} \mathrm{C}$ because it was the conditioned ambient temperature of the room. The desorption was performed in the injection port of the GC, in the splitless mode during $5 \mathrm{~min}$ at $240^{\circ} \mathrm{C}$.

The presence of matrix effect was observed because of the difference between the standard and spiked samples curves slopes. The ANOVA test showed that there were statistically significant differences $(p<0.01)$ for both cases. For that reason, the standard addition method was recommended for quantification studies. The results showed a good linearity with regression coefficient of 0.9965 and 0.9990 for azoxystrobin and pyraclostrobin, respectively.

The repeatability of the method was determined by performing ten replicates of a single extracting solution from azoxystrobin and pyraclostrobin spiked blueberry samples. The relative standard deviations (RSDs) obtained showed that duplicates assure deviation lower than $10 \%$ for the seven concentration levels studied. These values indicate that the precision of the method was satisfactory for control residue analysis.

LOD and LOQ were calculated as three and ten times the signal-to-noise ratio, respectively, in the analysis of spiked fruits (expressed as $\mu \mathrm{g} / \mathrm{kg}$ ). The LOD were 2.0 and 26.0; and the LOQ were 6.0 and $86.0 \mu \mathrm{g} / \mathrm{kg}$, for azoxystrobin and pyraclostrobin, respectively. These values satisfy the MRL established by the EC and means that the method is sufficiently sensitive. The LOD and LOQ of this method are smaller for azoxystrobin than those obtained by Caldas et al. [27] and Bolaños et al. [28]. Kolberg et al. [29] published similar values for this fungicide in wheat grains, flour and bran. Economou et al. [13] developed a more sensitive methodology based HPLC-MS/MS detection for wine with LOD and LOQ of 0.8 and $2.6 \mu \mathrm{g} / \mathrm{l}$, respectively.

To our knowledge does not exist any methodology for pyraclostrobin in blueberries, but in other substrates there is a big range of values for LOD, for instance, Banerjee et al. [11] published a value of $1 \mu \mathrm{g} / \mathrm{kg}$ in grapes and Lesueur et al. [30] $115 \mu \mathrm{g} / \mathrm{kg}$ in the same fruit.

In addition, to evaluate the accuracy of the method, a recovery study was carried out. The recovery values and the RSD for azoxystrobin were $106 \pm 3$ for the lowest concentration, $102 \pm 1$ for $100 \mu \mathrm{g} / \mathrm{kg}$, and $100 \pm 1$ for the highest concentration. The results obtained for pyraclostrobin were $106 \pm 2$; $96 \pm 2$; and $101 \pm 3$, respectively. The methodologies described by Banerjee et al. [11] and Fenoll et al. [1] were less accurate for both pesticides.

\subsection{Degradation of Azoxystrobin and Pyraclostrobin}

The commercial product used in the field had a concentration of $0.0470 \pm 0.0005 \mathrm{mg} / \mathrm{l}$ of azoxystrobin and $0.128 \pm 0.003 \mathrm{mg} / \mathrm{l}$ of pyraclostrobin. Residues of azoxystrobin and pyraclostrobin were determined in blueberry fruits collected from the evaluated lots in 2010-2011 harvested seasons. They were analyzed in triplicate and the mean values and the standard deviations are shown in Figure 4. The initial deposits of azoxystrobin in blueberries were 0.38 and $0.23 \mathrm{mg} / \mathrm{kg}$, and they declined quickly with time, with 55.6 and $57.7 \%$ of the initial amount found 10 days after application, for Emerald and Jewel cultivars respectively. On the other hand, the initial deposits of pyraclostrobin were 0.62 and $0.24 \mathrm{mg} / \mathrm{kg}$, and they declined quickly with time, with 7.9 and $13.1 \%$ of the initial amount after 20 days, for Emerald and Jewel cultivars respectively.

Loss of azoxystrobin and pyraclostrobin in blueberries followed a first order kinetics. The degradation parameters are summarized in Table 1 and Table 2 . The regression coefficients $R^{2}$ demonstrate the goodness of the model.

The comparison between Emerald and Jewel regression curves is shown in Figure 4(c). The ANOVA test showed that there were statistically significant differences $(\mathrm{p}<0.01)$.

The half-life for azoxystrobin was 11.6 and 17.8 days for Emerald and Jewel cultivars, respectively; and for pyraclostrobin was 5.5 and 8.0 days for Emerald and Jewel cultivars, respectively.

There are differences comparing the half-life of azoxystrobin and pyraclostrobin in both cultivars. Both blueberry cultivars had similar initial diameters, $8.8 \pm 1.0 \mathrm{~mm}$ for azoxystrobin, and $10.4 \pm 1.0 \mathrm{~mm}$ for pyraclostrobin applications. However, Emerald cultivar presented an average diameter of $16.5 \mathrm{~mm}$, while Jewel cultivar diameter was $14.6 \mathrm{~mm}$ after 20 days for pyraclostrobin, and for azoxystrobin were $18.2 \mathrm{~mm}$ for Emerald and 

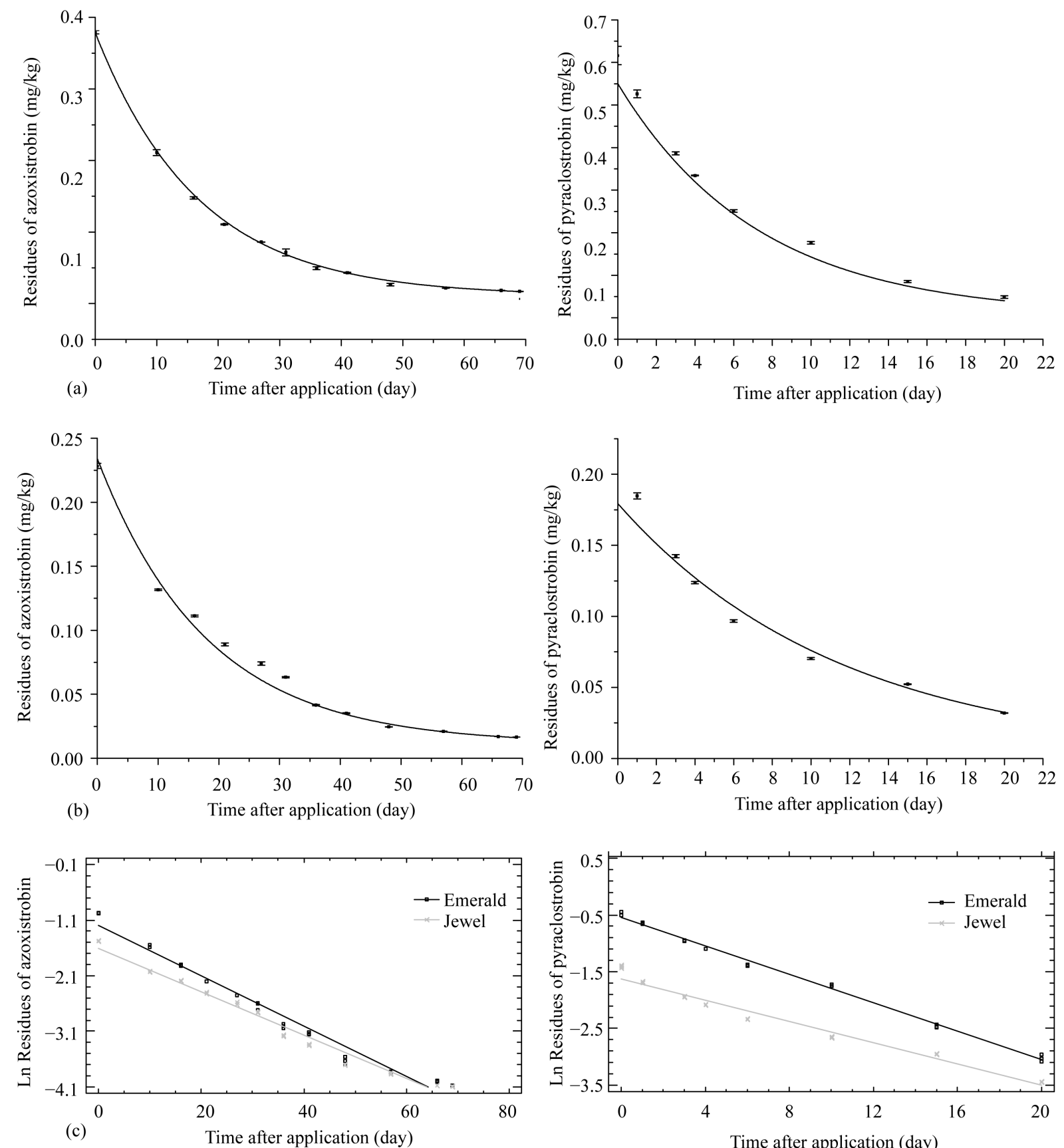

Figure 4. Degradation of azoxystrobin and pyraclostrobin in blueberry fruits (day 0, 10, 16, 21, 27, 31, 36, 41, 48, 57, 66 and 69 after application for azoxystrobin day $0,1,3,4,6,10,15$ and 20 for pyraclostrobin): Emerald cultivar $\mathrm{R}^{2} 0.9977$ and 0.9962 , respectively (a); Jewel cultivar $\mathrm{R}^{2} 0.9781$ and 0.9794 , respectively (b); Comparison between regression curves applying Ln of the concentration of fungicide (c).

Table 1. Kinetics parameters of azoxystrobin degradation in blueberry fruits.

\begin{tabular}{ccccc}
\hline Blueberry cultivar & Regression equation $^{\mathrm{a}}$ & $\mathrm{R}^{2}$ & ${\text { Rate constant }\left(\mathrm{k}, \text { day }^{-1}\right)}^{\text {Half-life }\left(\mathrm{t}_{1 / 2}, \text { day) }\right.}$ \\
\hline Emerald & $\mathrm{C}=0.01087+0.36803 \mathrm{e}^{-0.0597 \mathrm{t}}$ & 0.9977 & $0.060 \pm 0.001$ & $11.6 \pm 0.1$ \\
Jewel & $\mathrm{C}=0.2 \mathrm{e}^{-0.039 \mathrm{t}}$ & 0.9781 & $0.039 \pm 0.001$ & $17.8 \pm 0.1$ \\
\hline
\end{tabular}

${ }^{\mathrm{a}} \mathrm{C}=$ concentration of azoxystrobin; $\mathrm{t}=$ time. 
Table 2. Kinetics parameters of pyraclostrobin degradation in blueberry fruits.

\begin{tabular}{ccccc}
\hline Blueberry cultivar & Regression equation $^{\mathrm{a}}$ & $\mathrm{R}^{2}$ & ${\text { Rate constant }\left(\mathrm{k}, \text { day }^{-1}\right)}^{\text {Half-life }\left(\mathrm{t}_{1 / 2} \text {, day) }\right.}$ \\
\hline Emerald & $\mathrm{C}=0.5779 \mathrm{e}^{-0.125 \mathrm{t}}$ & 0.9962 & $0.125 \pm 0.001$ & $5.5 \pm 0.1$ \\
Jewel & $\mathrm{C}=0.17859 \mathrm{e}^{-0.08658 \mathrm{t}}$ & 0.9794 & $0.086 \pm 0.001$ & $8.0 \pm 0.1$ \\
\hline
\end{tabular}

${ }^{\mathrm{a}} \mathrm{C}=$ concentration of pyraclostrobin; $\mathrm{t}=$ time.

15.6 for Jewel cultivar. The growth dilution could be responsible for the differences in half-life and degradation rate found between both varieties. Further investigation is needed.

Based in an extensive analysis of the literature, there are not previous references about azoxystrobin and pyraclostrobin degradation in blueberries.

\section{Conclusions}

This study provides a method which gives distinct advantages over the typical techniques by minimizing the sample quantity to only $5 \mathrm{~g}$, followed by an extraction procedure that use only $25 \mathrm{ml}$ water. The use of water in the extraction step makes this methodology cheaper than those based on SPE or QuEChERS. In addition, organic solvents are not used. The method shows satisfactory precision and accuracy with detection limits that are lower than the MRL needed for example to Europe exportation. Based in a thorough analysis of the available literature, it is the first time that SPME is applied in the determination of azoxystrobin and pyraclostrobin in blueberries.

The degradation of azoxystrobin and pyraclostrobin in both blueberry varieties studied followed a first order rate kinetics, and an exponential model was applied. The half-life from both cultivars showed significant differences, and this could be attributed to growth dilution and chemical characteristics from each cultivar.

\section{Acknowledgements}

The authors acknowledge to Agencia Nacional de Promoción Científica y Tecnológica, Comisión de Investigaciones Científicas de la Provincia de Buenos Aires, Universidad de Buenos Aires and Universidad de Entre Ríos for financial support.

\section{References}

[1] Fenoll, J., Hellín, P., Martínez, C. M., Miguel, M. and Flores, P. (2007) Multiresidue Method for Analysis of Pesticides in Pepper and Tomato by Gas Chromatography with Nitrogen-Phosphorus Detection. Food Chemistry, 105, 711-719. http://dx.doi.org/10.1016/j.foodchem.2006.12.060

[2] Belmonte Valles, N., Retamal, M., Mezcua, M. and Fernández-Alba, A.R. (2012) A Sensitive and Selective Method for the Determination of Selected Pesticides in Fruit by Gas Chromatography/Mass Spectrometry with Negative Chemical Ionization. Journal of Chromatography A, 1264, 110-116. http://dx.doi.org/10.1016/j.chroma.2012.09.063

[3] Čajka, T., Sandy, C., Bachanova, V., Drabova, L., Kalachova, K., Pulkrabova, J. and Hajšlová, J. (2012) Streamlining Sample Preparation and Gas Chromatography-Tandem Mass Spectrometry Analysis of Multiple Pesticide Residues in Tea. Analytica Chimica Acta, 743, 51-60. http://dx.doi.org/10.1016/j.aca.2012.06.051

[4] Cazorla-Reyes, R., Fernández-Moreno, J.L., Romero-González, R., Garrido Frenich, A. and Martínez Vidal, J.L. (2011) Single Solid Phase Extraction Method for the Simultaneous Analysis of Polar and Non-Polar Pesticides in Urine Samples by Gas Chromatography and Ultra High Pressure Liquid Chromatography Coupled to Tandem Mass Spectrometry. Talanta, 85, 183-196. http://dx.doi.org/10.1016/j.talanta.2011.03.048

[5] Cunha, S.C. and Fernandes, J.O. (2011) Multipesticide Residue Analysis in Maize Combining Acetonitrile-Based Extraction with Dispersive Liquid-Liquid Microextraction Followed by Gas Chromatography-Mass Spectrometry. Journal of Chromatography A, 1218, 7748-7757. http://dx.doi.org/10.1016/j.chroma.2011.08.066

[6] Cus, F., Cesnik, H.B., Bolta, S.V. and Gregorcic, A. (2010) Pesticide Residues and Microbiological Quality of Bottled Wines. Food Control, 21, 150-154. http://dx.doi.org/10.1016/j.foodcont.2009.04.010

[7] Lee, K.-G and Jo, E.-K. (2012) Multiresidue Pesticide Analysis in Korean Ginseng by Gas Chromatography-Triple Quadrupole Tandem Mass Spectrometry. Food Chemistry, 134, 2497-2503. http://dx.doi.org/10.1016/j.foodchem.2012.04.094

[8] Walorczyk, S. (2012) Gas Chromatographic-Tandem Mass Spectrometric Analysis of Pesticides Residues in Produce 
Using Concurrent Solvent Recondensation-Large Volume Injection. Journal of Chromatography A, 1222, 98-108. http://dx.doi.org/10.1016/j.chroma.2011.12.012

[9] Walorczyk, S. and Drozdzynski, D. (2012) Improvement and Extension to New Analytes of a Multi-Residue Method for the Determination of Pesticides in Cereals and Dry Animal Feed Using Gas Chromatography-Tandem Quadrupole Mass Spectrometry Revisited. Journal of Chromatography A, 1251, 219-231. http://dx.doi.org/10.1016/j.chroma.2012.06.055

[10] Alder, L., Lüderitz, S., Lindtner, K. and Stan, H.-J. (2004) The ECHO Technique-The More Effective Way of Data Evaluation in Liquid Chromatography-Tandem Mass Spectrometry Analysis. Journal of Chromatography A, 1058, 6779. http://dx.doi.org/10.1016/j.chroma.2004.08.120

[11] Banerjee, K., Oulkar, D.P., Dasgupta, S., Patil, S.B., Patil, S.H., Savant, R. and Adsule, P.G. (2007) Validation and Uncertainty Analysis of a Multi-Residue Method for Pesticides in Grapes Using Ethyl Acetate Extraction and Liquid Chromatography-Tandem Mass Spectrometry. Journal of Chromatography A, 1173, 98-109. http://dx.doi.org/10.1016/j.chroma.2007.10.013

[12] Coscollà, C., Yusà, V., Beser, M.I. and Pastor, A. (2009) Multi-Residue Analysis of 30 Currently Used Pesticides in Fine Airborne Particulate Matter (PM 2.5) by Microwave-Assisted Extraction and Liquid Chromatography-Tandem Mass Spectrometry. Journal of Chromatography A, 1216, 8817-8827. http://dx.doi.org/10.1016/j.chroma.2009.06.031

[13] Economou, A., Botitsi, H., Antoniou, S. and Tsipi, D. (2009) Determination of Multi-Class Pesticides in Wines by Solid-Phase Extraction and Liquid Chromatography-Tandem Mass Spectrometry. Journal of Chromatography A, 1216, 5856-5867. http://dx.doi.org/10.1016/j.chroma.2009.06.031

[14] Luan, Y.S., Feng, L., Xia, X.Y. and An, L.J. (2007) First Report of Alternaria tenuissima Causing Disease on Blueberry in China. Plant Disease, 91, 464. http://dx.doi.org/10.1094/PDIS-91-4-0464A

[15] Munitz, M.S., Garrido, C.E., Gonzalez, H.H.L., Resnik, S.L., Salas, P.M. and Montti, M.I.T. (2013) Mycoflora and Potential Mycotoxin Production of Freshly Harvested Blueberry in Concordia, Entre Ríos Province, Argentina. International Journal of Fruit Science, 13, 312-325. http://dx.doi.org/10.1080/15538362.2013.748374

[16] Rivera, M.C., Wright, E.R., Pérez, B.A., Rabelino, P.G. and Pérez, J.A. (2009) Enfermedades del Arándano. In: Gráfica, O. and Wright, E.R., Eds., Guía de Enfermedades, Insectos y Malezas del Arándano, Orientación Gráfica, Buenos Aires, 1-68.

[17] Tournas, V.H. and Katsoudas, E. (2005) Mould and Yeast Flora in Fresh Berries, Grapes and Citrus Fruits. International Journal of Food Microbiology, 105, 11-17. http://dx.doi.org/10.1016/j.ijfoodmicro.2005.05.002

[18] Vásquez, P., Baldomá, J.A., Wright, E.R., Pérez, A. and de Sesar, M.D. (2007) First Report of Blueberry Botrytis Blight in Buenos Aires, Entre Ríos, and Córdoba, Argentina. Plant Disease, 91, 639. http://dx.doi.org/10.1094/PDIS-91-5-0639C

[19] Wharton, P.S. and Schilder, A.C. (2008) Novel Infection Strategies of Colletotrichum acutatum on Ripe Blueberry Fruit. Plant Pathology, 57, 122-134.

[20] Regulation (EC) No. 396/2005 of the European Parliament and of the Council of 23 February 2005 on Maximum Residue Levels of Pesticides in or on Food and Feed of Plant and Animal Origin and Amending Council Directive 91/414/EEC. Official Journal of the European Union, L70, 1-16.

[21] Filho, A.M., Santos, F.N.D and Pereira, P.A. (2010) Development, Validation and Application of a Methodology Based on Solid-Phase Micro Extraction Followed by Gas Chromatography Coupled to Mass Spectrometry (SPME/GCMS) for the Determination of Pesticide Residues in Mangoes. Talanta, 81, 346-354. http://dx.doi.org/10.1016/j.talanta.2009.12.008

[22] Filho, A.M., Santos, F.N.D and Pereira, P.A. (2010) Development, Validation and Application of a Method Based on DI-SPME and GC-MS for Determination of Pesticides of Different Chemical Groups in Surface and Groundwater Samples. Microchemical Journal, 96, 139-145. http://dx.doi.org/10.1016/j.microc.2010.02.018

[23] Viñas, P., Campillo, N., Martínez-Castillo, N. and Hernández-Córdoba, M. (2009) Method Development and Validation for Strobilurin Fungicides in Baby Foods by Solid-Phase Microextraction Gas Chromatography-Mass Spectrometry. Journal of Chromatography A, 1216, 140-146. http://dx.doi.org/10.1016/j.chroma.2008.11.036

[24] Chai, M.K. and Tan, G.H. (2009) Validation of a Headspace Solid-Phase Microextraction Procedure with Gas Chromatography-Electron Capture Detection of Pesticide Residues in Fruits and Vegetables. Food Chemistry, 117, 561-567. http://dx.doi.org/10.1016/j.foodchem.2009.04.034

[25] Fytianos, K., Raikos, N., Theodoridis, G., Velinova, Z. and Tsoukali, H. (2006) Solid Phase Microextraction Applied to the Analysis of Organophosphorus Insecticides in Fruits. Chemosphere, 65, 2090-2095. http://dx.doi.org/10.1016/j.chemosphere.2006.06.046

[26] Tsoukali, H., Theodoridis, G., Raikos, N. and Grigoratou, I. (2005) Solid Phase Microextraction Gas Chromatographic Analysis of Organophosphorus Pesticides in Biological Samples. Journal of Chromatography B, 822, 194-200. 
http://dx.doi.org/10.1016/j.jchromb.2005.05.035

[27] Caldas, S.S., Bolzan, C.M., Cerqueira, M.B., Tomasini, D., Furlong, E.B., Fagundes, C. and Primel, E.G. (2011) Evaluation of a Modified QuEChERS Extraction of Multiple Classes of Pesticides from a Rice Paddy Soil by LC-APCIMS/MS. Journal of Agricultural and Food Chemistry, 59, 11918-11926. http://dx.doi.org/10.1021/jf202878s

[28] Bolaños, P.P., Moreno, J.L.F., Shtereva, D.D., Frenich, A.G. and Vidal, J.L.M. (2007) Development and Validation of a Multiresidue Method for the Analysis of 151 Pesticide Residues in Strawberry by Gas Chromatography Coupled to a Triple Quadrupole Mass Analyzer. Rapid Communication in Mass Spectrometry, 21, 2282-2294. http://dx.doi.org/10.1002/rcm.3091

[29] Kolberg, D.I., Prestes, O.D., Adaime, M.B. and Zanella, R. (2011) Development of a Fast Multiresidue Method for the Determination of Pesticides in Dry Samples (Wheat Grains, Flour and Bran) Using QuEChERS Based Method and GC-MS. Food Chemistry, 125, 1436-1442. http://dx.doi.org/10.1016/j.foodchem.2010.10.041

[30] Lesueur, C., Knittl, P., Gartner, M., Mentler, A. and Fuerhacker, M. (2008) Analysis of 140 Pesticides from Conventional Farming Foodstuff Samples after Extraction with the Modified QuECheRS Method. Food Control, 19, 906-914. http://dx.doi.org/10.1016/j.foodcont.2007.09.002 
Scientific Research Publishing (SCIRP) is one of the largest Open Access journal publishers. It is currently publishing more than 200 open access, online, peer-reviewed journals covering a wide range of academic disciplines. SCIRP serves the worldwide academic communities and contributes to the progress and application of science with its publication.

Other selected journals from SCIRP are listed as below. Submit your manuscript to us via either submit@scirp.org or Online Submission Portal.
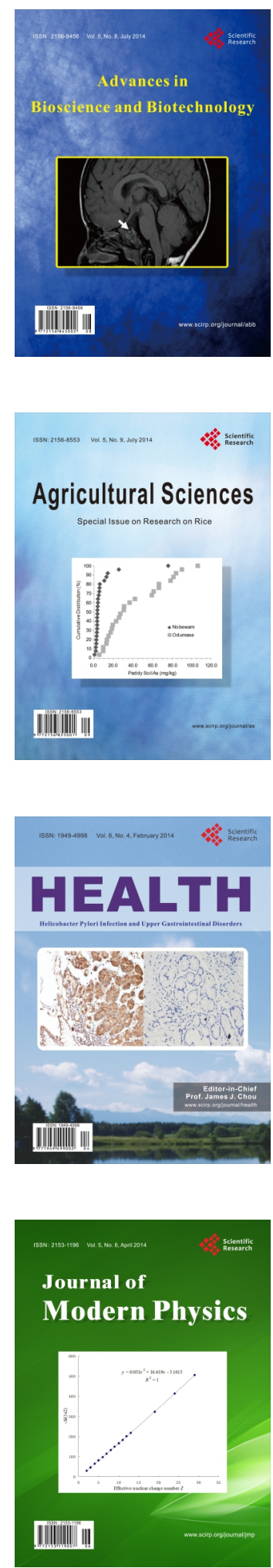
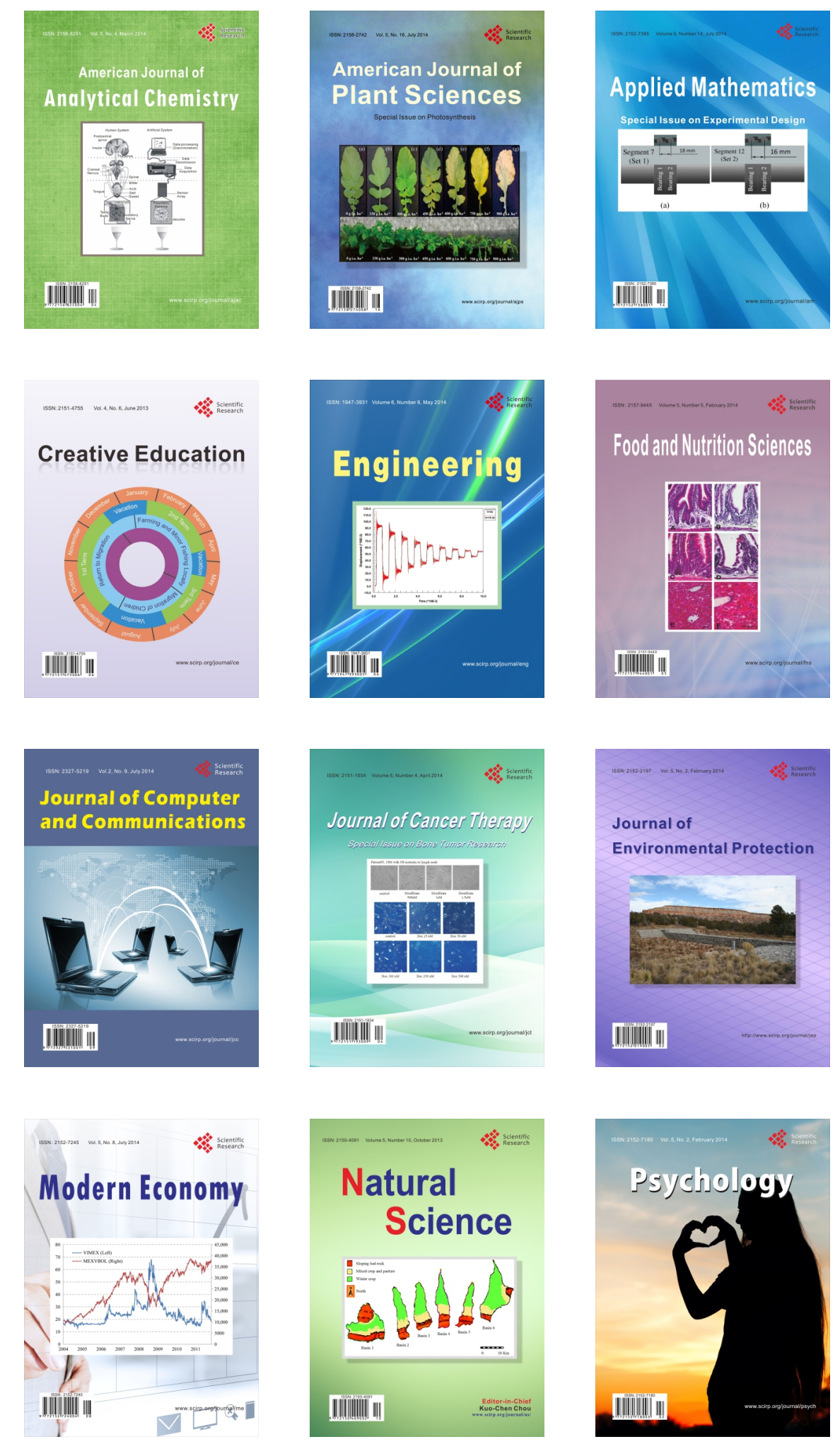